Germanistische Abhandlungen

Vergleichung 
HeNDRIK Birus

\section{Vergleichung}

Goethes Einführung in die Schreibweise

Jean Pauls

J.B. METZLERSCHE VERLAGSBUCHHANDLUNG STUTTGART 
GERMANISTISCHE ABHANDLUNGEN 59

CIP-Kurztitelaufnahme der Deutschen Bibliothek

Birus, Hendrik:

Vergleichung: Goethes Einf.

in d. Schreibweise Jean Pauls /

Hendrik Birus.

- Stuttgart: Metzler, 1986.

(Germanistische Abhandlungen; 59)

ISBN 978-3-476-00591-5

ISBN 978-3-476-03223-2 (eBook)

DOI 10.1007/978-3-476-03223-2

NE: GT

ISSN 0435-5903

(C) 1986 Springer-Verlag GmbH Deutschland

Ursprünglich erschienen bei J.B. Metzlersche Verlagsbuchhandlung und Carl Ernst Poeschel Verlag GmbH in Stuttgart 1986 
»Ins Unendliche reichen diese Vergleichungen, und am Ende ist man nicht einmal am Anfange.«

(Jean Paul, Vorrede zur Vorschule der Aesthetik) 


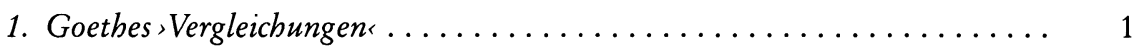

Spielarten der Vergleichung in Goethes Literatur- und Kunstkritik - Deskriptive vs. normative Vergleichungen

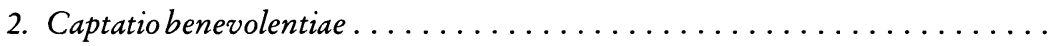

Nochmals pro und contra Vergleichungen

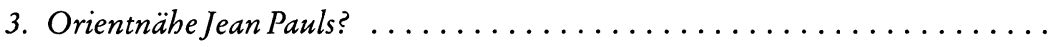

Hammer-Purgstall als Gewährsmann - Orientbezüge bei Jean Paul - Görres' IndienVergleiche - Goethes "Chinese in Rom« - Der »Hesperus« als »Tragelaph« - AntiManierismus-Polemik

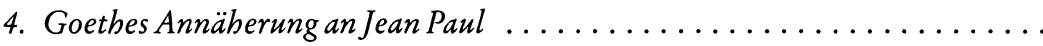

Werk und Persönlichkeit des Autors - Goethes langjährige Jean-Paul-Aversion - Geschmackswandel - Disparates und `ethischer Faden « - OOrientalische Weise ‘ Jean Pauls

5. Die orientalische Poesie als Bezugspunkt ...............

Goethes Beschwörung des Orients - Hebräische Poesie - Altpersische ÜberlieferungFrüharabische Poesie - Entwicklungstendenzen der arabischen und persischen Poesie

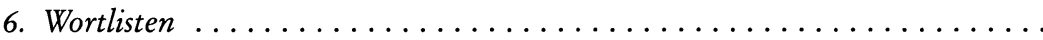

>Naturelementes der arabischen Poesie - Katalog orientalischer Tropen - Goethes Wortliste und F. Schlegels Fremdwortverzeichnis aus dem "Wilhelm Meister - Jean Paul und Goethe zum Sprachpurismus

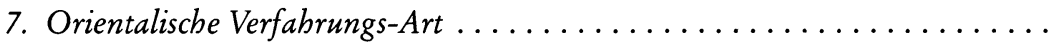

Schwierigkeiten beim Lesen Jean Pauls - Lexikalische Hilfsmittel - Realitätsbezug orientalischer Dichtung - Vergleichstechnik der arabischen Poesie - Metapherntechnik der persischen Poesie - Ihre Behandlung durch Goethe

8. Poetische Enzyklopädie

Kritik und Selbstkritik von Jean Pauls witziger Schreibweise - Apologie des sgelehrten Witzes - Kollektaneen - Übergang von Vergleichen zu Metaphern - Exzerptenordnung - Witziges Individualisieren ->Ähnlichkeit` vs. >Heterogenität im Witz-Begriff Künstlichkeit der Moderne - Der späte Goethe über Gleichnisse und Tropen - >Symbok vs. 'Allegorier - 'geistreich 


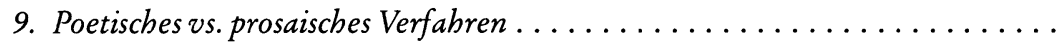

Poesie und Prosa - Poetische Äquivalenzen - Poetische Kunstgriffe - Prosa als problematische Form - Jean Pauls Abneigung gegen Verszwang - Apologie der Prosaform Kritik des , Geschmacks

10. Witzige Illumination

IIngeniöser`vs. geselliger Witz - Rätselkunst - Charaden - Relativierung des ,Witzes`

11. Epilog

Anhang

Historisch-kritische Textwiedergabe von Goethes Bezugsstelle aus Jean Pauls "Hesperus"

Anmerkungen

Literaturverzeichnis 


\title{
JohanN WoLfgang von Goethe
}

\author{
Vergleichung
}

Da wir nun so eben bei dem Urtheil über Schriftsteller alle Vergleichung abgelebnt, so möchte man sich wundern, wenn wir unmittelbar darauf von einem Falle sprechen, in welchem wir sie zulässig finden. Wir hoffen jedoch, daß man uns diese Ausnabme darum erlauben werde, weil der Gedanke nicht uns, vielmehr einem dritten angebört.

Ein Mann, der des Orients Breite, Höben und Tiefen durchdrungen, findet daß kein deutscher Schriftsteller sich den östlichen Poeten und sonstigen Verfassern mebr als Jean Paul Richter genäbert habe; dieser Ausspruch schien zu bedeutend, als daß wir ibm nicht gehörige Aufmerksamkeit hätten widmen sollen; auch können wir unsere Bemerkungen darüber um so leichter mittheilen, als wir uns nur auf das oben weitläufig Durchgefübrte beziehen dürfen.

Allerdings zeugen, um von der Persönlichkeit anzufangen, die Werke des genannten Freundes von einem verständigen, umschauenden, einsichtigen, unterrichteten, ausgebildeten und dabei woblwollenden, frommen Sinne. Ein so begabter Geist blickt, nach eigentlichst orientalischer Weise, munter und kübn in seiner Welt umber, erschafft die seltsamsten Bezüge, verknüpft das Unverträgliche, jedoch dergestalt, daß ein gebeimer ethischer Faden sich mitschlinge, wodurch das Ganze zu einer gewissen Einheit geleitet wird.

Wenn wir nun vor kurzem die Natur-Elemente, woraus die älteren und vorzüglichsten Dichter des Orients ibre Werke bildeten, angedeutet und bezeichnet, so werden wir uns deutlich erklären, indem wir sagen: daß, wenn jene in einer frischen, einfachen Region gewirkt, dieser Freund bingegen in einer ausgebildeten, überbildeten, verbildeten, vertrackten Welt leben und wirken, und eben daber sich anschicken muß die seltsamsten Elemente zu beherrschen. Um nun den Gegensatz zwischen der Umgebung eines Beduinen und unseres Autors mit wenigem anschaulich zu machen, ziehen wir aus einigen Blättern die bedeutendsten Ausdrücke:

Barrieren-Tractat, Extrablätter, Cardinäle, Nebenreceß, Billard, Bierkrüge, Reichsbänke, Sessionsstüble, Prinzipalcommissarius, Enthusiasmus, Zepter-Queue, Bruststücke, Eichbornbauer, Agioteur, Schmutzfink, Incognito, Colloquia, kanonischer Billardsack, Gypsabdruck, Avancement, Hüttenjunge, Naturalisations-Acte, Pfingstprogramm, Maurerisch, Manual-Pantomime, Amputirt, Supranumerar, Bijouteriebude, Sabbaterweg u.s.f.

Wenn nun diese sämmtlichen Ausdrücke einem gebildeten deutschen Leser bekannt sind, oder durch das Conversations-Lexicon bekannt werden können, gerade wie dem Orientalen die Außenwelt durch Handels- und Wallfabrts-Caravanen; so dürfen wir 
kübnlich einen äbnlichen Geist für berechtigt balten dieselbe Verfabrungs-Art auf einer völlig verschiedenen Unterlage walten zu lassen.

Gestehen wir also unserm so geschätzten als fruchtbaren Schriftsteller zu, daß er, in späteren Tagen lebend, um in seiner Epoche geistreich zu seyn, auf einen, durch Kunst, Wissenschaft, Technik, Politik, Kriegs- und Friedensverkehr und Verderb so unendlich verclausulirten, zersplitterten Zustand mannigfaltigst anspielen müsse; so glauben wir ibm die zugesprochene Orientalität genugsam bestätigt zu haben.

Einen Unterschied jedoch, den eines poetischen und prosaischen Verfabrens, heben wir hervor: Dem Poeten, welchem Tact, Parallel-Stellung, Sylbenfall, Reim die größten Hindernisse in den Weg zu legen scheinen, gereicht alles zum entschiedensten Vortheil, wenn er die Rätbselknoten glücklich löst, die ibm aufgegeben sind, oder die er sich selbst aufgiebt; die kübnste Metapher verzeiben wir wegen eines unerwarteten Reims und freuen uns der Besonnenheit des Dichters, die er, in einer so nothgedrungenen Stellung, behauptet.

Der Prosaist hingegen hat die Ellebogen gänzlich frei und ist für jede Verwegenbeit verantwortlich, die er sich erlaubt; alles was den Geschmack verletzen könnte kommt auf seine Rechnung. Da nun aber, wie wir umständlich nachgewiesen, in einer solchen Dichtund Schreibart das Schickliche vom Unschicklichen abzusondern unmöglich ist; so kommt bier alles auf das Individuum an, das ein solches Wagstück unternimmt. Ist es ein Mann, wie Jean Paul, als Talent von Werth, als Mensch von Würde, so befreundet sich der angezogene Leser sogleich; alles ist erlaubt und willkommen. Man füblt sich in der Näbe des wobldenkenden Mannes behaglich, sein Gefübl theilt sich uns mit. Unsere Einbildungskraft erregt er, schmeichelt unseren Schwächen und festiget unsere Stärken.

Man übt seinen eigenen Witz, indem man die wunderlich aufgegebenen Räthsel zu lösen sucht, und freut sich in und hinter einer buntverschränkten Welt, wie hinter einer andern Charade, Unterhaltung, Erregung, Rübrung, ja Erbauung zu finden.

Dieß ist ungefäbr was wir vorzubringen wußten, um jene Vergleichung zu rechtfertigen; Übereinstimmung und Differenz trachteten wir so kurz als möglich auszudrücken; ein solcher Text könnte zu einer gränzenlosen Auslegung verfübren. 